\title{
The Effect of Psychotherapy on Anxiety, Depression, and Quality of Life of Patients with Heart Failure: A Randomized Clinical Trial
}

Isaura Rocha, ${ }^{1,2}$ Ana Dantas Cavalcanti, ${ }^{\oplus}$ Lyvia Figueiredo, ${ }^{\circledR}$ Juliana Pereira, ${ }^{\circledR}$ Samara de Oliveira, ${ }^{\circledR}$ Danilo da Cruz, ${ }^{\oplus}$ Rodrigo de Freitas, ${ }^{1 \oplus}$ Evandro Tinoco Mesquitar ${ }^{1 \odot}$

Universidade Federal Fluminense, Niterói, RJ-Brazil

Hospital Pró-Cardíaco, ${ }^{2}$ Rio de Janeiro, RJ - Brazil

\section{Abstract}

Background: Patients with heart failure often experience depression, anxiety, and impacts on quality of life. Psychotherapeutic interventions have been used for chronic conditions, including cardiovascular diseases, showing improvement in mental health. However, no studies have assessed the effects of a psychological intervention using psychoanalysis on patients with heart failure.

Objective: To assess the effect of short-term psychotherapy on depressive symptoms, anxiety, and quality of life of patients seen at a specialty clinic.

Method: A randomized clinical trial with scales to assess outcomes before and after psychotherapy, under the perspective of psychoanalysis, with 12 weekly sessions. The Beck Depression Inventory, the Beck Anxiety Inventory, and the Minnesota Living with Heart Failure Questionnaire were used. The mean initial and final scores for quality of life, anxiety, and depression were compared using Student's t-test for independent samples when distribution was normal, or Mann-Whitney test when distribution was non-normal. A bivariate p-value $<0.05$ was considered statistically significant for all analyses.

Results: This study involved 32 patients, $50 \%$ were female, mean age was $64.3 \pm 11.6$, and most participants were New York Heart Association (NYHA) functional class I (56.3\%). For anxiety $(p=0.196)$, there was no statistically significant difference between groups. For quality of life and depression, there was a statistical difference $(\mathrm{p}=0.009$ and 0.035 , respectively), with a medium effect (Cohen's $d=0.593$ ) on quality of life.

Conclusion: Short-term psychotherapy in outpatients with heart failure showed an impact on depression and quality of life but did not improve anxiety. (Int J Cardiovasc Sci. 2021; 34(2):188-196)

Keywords: Heart Failure; Anxiety; Depression; Quality of Life; Psychotherapy; Mental Health; Psychoanalytic Therapy.

\section{Introduction}

According to the World Health Organization, ${ }^{1}$ billions of people will die worldwide from chronic noncommunicable diseases, especially cardiovascular conditions. Patients with heart disease are an object of interest in the field of mental health because of the impacts on the subjects' lives; therefore, mind and heart are closely interconnected. ${ }^{2}$

Heart failure (HF) is a complex and progressive clinical syndrome ${ }^{3}$ in which the heart is unable to pump efficiently to supply the body's needs, seeking compensatory hemodynamic pathways. Thus, common symptoms are dyspnea, fatigue, tiredness, exercise intolerance, weight gain, loss of appetite, nocturia, and oliguria. ${ }^{4}$ The main risk factors for hypertension are hypercholesterolemia, coronary artery disease, diabetes mellitus, smoking, and obesity. ${ }^{5}$

HF is little recognized both by the population and the political power, and affects $1 \%$ to $2 \%$ of the population worldwide, with an estimated growth of $25 \%$ until $2030 .{ }^{6}$

Mailing Address: Isaura Rocha

Av. Marquês do Paraná, 303. Postal code: 24220-900, Niterói, RJ - Brazil.

E-mail: isaura.rocha@uol.com.br 
In the United States and Europe, it is the leading cause of hospitalization for older individuals, with a very significant socioeconomic impact, being accountable for $68 \%$ of hospitalization expenses. ${ }^{6}$ In Brazil, cardiovascular diseases are the main cause of death, affecting $20 \%$ of people over 30 years old. ${ }^{7}$ It is noteworthy that $50 \%$ of all hospitalized patients are readmitted within 90 days, which is one of the main risk factors for death. ${ }^{8}$

I Brazilian Registry of Heart Failure (BREATHE) ${ }^{8}$ described high in-hospital mortality related to low rates of evidence-based therapy. Poor adherence to treatment is one of the main factors for decompensation. Moreover, depression is prevalent in hospitalized patients, with an average ranging from $15 \%$ to $36 \%{ }^{4}$ This association makes adherence to treatment more difficult, increases hospitalizations, and elevates morbidity and mortality. ${ }^{9}$ The coexistence between depressive and anxiety symptoms directly impacts quality of life. ${ }^{10}$ Thus, it is essential that health professionals detect and treat such conditions early, in addition to developing new studies to define effective interventions. ${ }^{11}$

In this regard, psychologists identify important obstacles, such as difficulty in understanding and accepting the disease and treatment, defense mechanisms, impasses or family conflicts, psychopathological conditions, among others. This reality was observed during psychological consultations at a specialty clinic in Niterói, Rio de Janeiro, Brazil, especially concerning the patients' physical, psychological, and social fragility, with reports of personal and family issues, depressive symptoms, anxiety, and impaired quality of life.

To our knowledge, no studies have assessed the effects of short-term psychotherapy on depression, anxiety, and quality of life of patients with HF. Therefore, this is a pioneer study that aims to assess the effects of short-term psychotherapy, under the perspective of psychoanalysis, on depression, anxiety, and quality of life of outpatients with HF.

\section{Method}

\section{Study design}

A randomized clinical trial (RCT) was conducted with two distinct parallel groups. This RCT aimed to test a psychological intervention consisting of short-term psychoanalytic listening in patients with HF seen at a specialty clinic.

\section{Participants}

Patients over 18 years old and classified as any New York Heart Association (NYHA) functional class were included. Psychotherapy patients who started using psychotropic drugs during intervention with severe neurological sequelae or severe psychiatric disorders were excluded. Participants were invited, by telephone or personal contact, to participate in the study at a specialty HF clinic, where all data were collected.

\section{Intervention}

Sociodemographic data were collected, informed consent was obtained, and then the scales were administered. Control group (CG) patients followed routine clinic visits, without psychotherapy; meanwhile, intervention group (IG) patients were scheduled to start psychotherapy with the study psychologist. The psychologist introduced participants to a shortterm psychological follow-up proposal based on a psychoanalytical approach aiming to improve depressive and anxiety symptoms and, consequently, their quality of life. This semistructured, flexible treatment plan tailored to each patient's personal demands (Treatment Plan - Annex 1) could involve, whenever possible, family members. Altogether, 12 weekly sessions were held.

Each session lasted 45 minutes, with duration monitored by a watch. The environment was maintained at a pleasant temperature (average of $23^{\circ} \mathrm{C}$ ), bright, with little outside noise, and included a table and two chairs (or three when there was a family member). Statements were not recorded. Session notes were taken later by the researcher.

The patients' statements showed the degree of understanding of the disease, adherence to treatment, social and family support, psychiatric history, and issues highlighted by them. The follow-up sessions addressed topics such as quality of life, lifestyle, personal, professional, religious, social, and family choices, sexuality, coping with the disease, and life itself. Patients were encouraged to talk about themselves and about aspects related to the disease, in addition to being encouraged to be assertive, to perform self-care, and to improve quality of life. Psychoanalysis, as a theoretical framework, was based on free association considering unconscious contents, insights, defense mechanisms, bonds, traumas, among other concepts, all considered in the proposed treatment plan. 


\section{Outcomes}

To assess anxiety, depression, and quality of life, the Beck Anxiety Inventory (BAI), the Beck Depression Inventory (BDI), and the Minnesota Living with Heart Failure Questionnaire (MLHFQ) were used, respectively. ${ }^{12-16}$

\section{Sample size}

The sample size was calculated with WinPepi 11.46, based on the sample calculation of two studies that used depression as an outcome based on BDI. The first study ${ }^{17}$ was conducted by a research group named "Heart failure: from the molecule to the population," which includes the main researcher and served as a pilot for this study because of the same patient profile. Mean score was $31.5 \pm 3.53$ before intervention and $50.5 \pm 13.4$ after intervention. The second study ${ }^{18}$ found the following: before intervention, scores were $29.6 \pm 10.2$ for CG and $30.7 \pm 10.2$ for IG; after intervention, scores were $16.0 \pm 10.6$ for CG and 11.2 \pm 10.7 for IG. We considered a sample of 16 patients in each group, with a difference of 17 points, $20 \%$ of losses, a significance level of $5 \%$, and a power of $80 \%$.

\section{Randomization}

Randomization was performed using a simple sequence, at www.randomization.com, considering 20\% of losses from an initial list with the names of patients who met the inclusion criteria.

\section{Statistical methods}

Data were organized by preparing and synthesizing a database with Microsoft Excel 2010. The data collected from the study instruments were tabulated and analyzed by SPSS, version 20.0. Categorical variables were expressed by frequency and percentage distributions and compared between groups using chi-square test and Fisher's exact test.

Continuous variables were expressed by mean and standard deviation or median and interquartile range according to the behavior of variables (normality) as identified by Kolmogorov-Smirnov test. Comparison of continuous variables between groups was performed by Student's t-test for independent samples or MannWhitney test.

Mean initial and final scores for quality of life, anxiety, and depression were also compared with Student's $\mathrm{t}$-test for independent samples when distribution was normal, or Mann-Whitney test when distribution was non-normal. A bivariate p-value $<0.05$ was considered statistically significant for all analyses.

The effect size was measured, which made it possible to add information to the concept of statistical significance. The effect size was calculated using Cohen's d.

\section{Ethical aspects}

This study was approved by the Research Ethics Committee of Hospital Universitário Antônio Pedro (REC/ HUAP), under Certificate of Presentation for Ethical Consideration (CAAE - Certificado de Apresentação para Apreciação Ética) no. 57827916.3.0000.5243.

All participants were informed about the objectives, risks, and benefits of the study, and their doubts were clarified. Then they completed the informed consent form and received a copy, as provided in Resolution no. 466/2012 of the Brazilian National Health Council (Conselho Nacional de Saúde). ${ }^{19}$ This study ensured the confidentiality and privacy of the data collected from all participants.

\section{Results}

Figure 1 represents the flowchart of selection of participants since recruitment, as recommended by the Consolidated Standards of Reporting Trials (CONSORT) 2010. ${ }^{20}$

Table 1 shows sociodemographic and clinical characteristics of the 32 participants, which included 16 women (50\%). There was no statistically significant difference when comparing the groups ( $p>0.05)$.

Table 2 shows the results of the initial interview regarding patients' self-perception, the areas they considered most affected by HF, their expectations, and their role in treatment.

Table 3 shows a comparison between the initial and final scores of IG and CG. There was a statistically significant difference between the groups in terms of quality of life and depression before and after intervention $(p<0.05)$. Psychotherapy proved to have a positive effect on these outcomes. Cohen's $\mathrm{d}^{21}$ was used for the outcome quality of life (0.593), which refers to the mean effect of the intervention performed. It was not possible to calculate the effect of the outcome depression; this calculation is only possible using mean and standard deviation, but depression was calculated using median. 


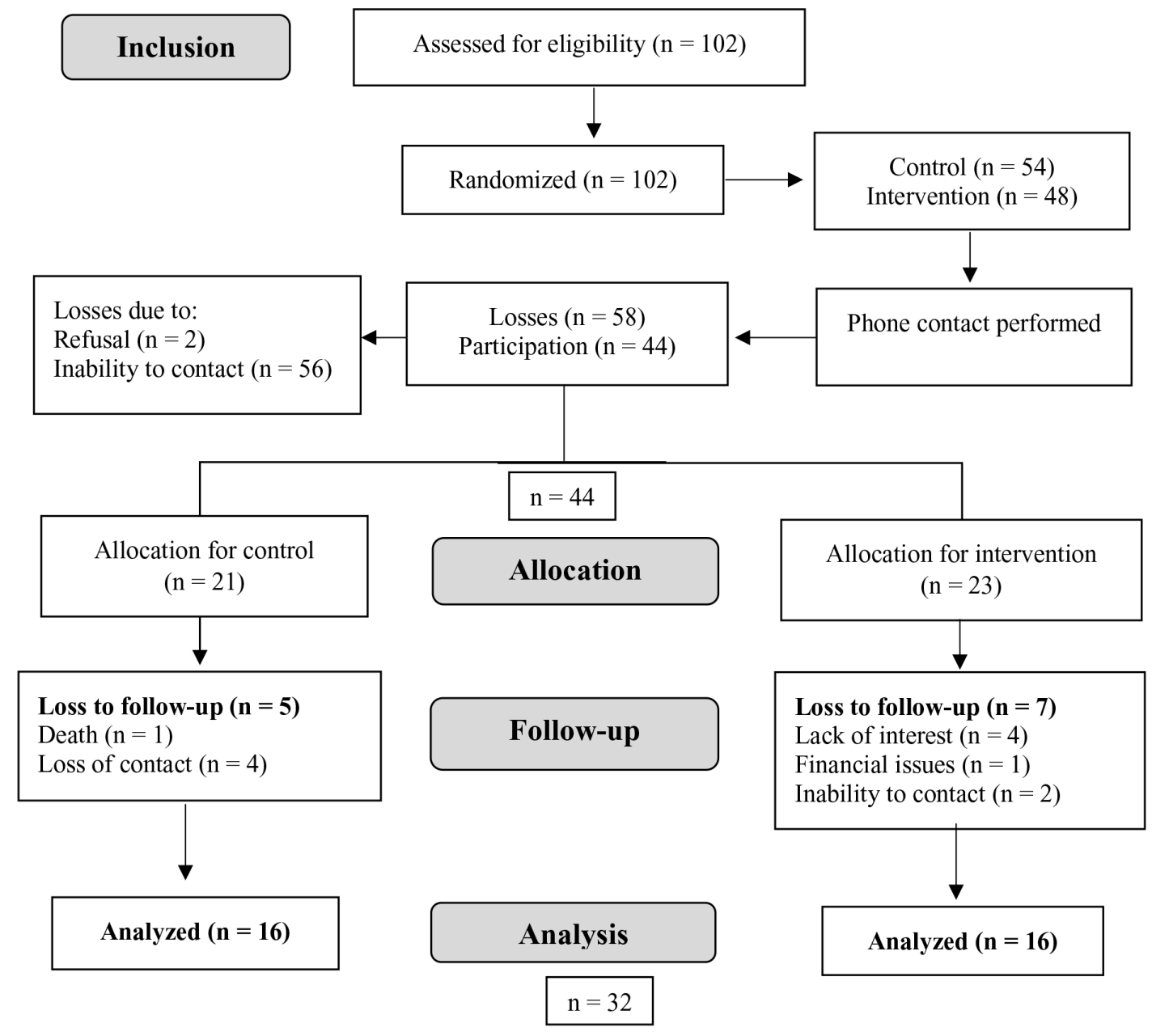

Figure 1 - Flowchart of selection of participants. Niterói, RJ, Brazil, 2019.

Source: created by the author based on CONSORT 2010. ${ }^{20}$.

\section{Discussion}

This study tested a short-term psychological intervention under the perspective of psychoanalysis and assessed its effect on the symptoms of anxiety, depression, and quality of life of patients with HF seen at a specialty clinic. The results demonstrated a positive effect of the proposed intervention for quality of life ( $p=0.009$; Cohen's $d=0.593$ ) and depression $(p=0.035)$ in patients with HF.

No study was found in the scientific literature assessing the effects of psychotherapy under the perspective of psychoanalysis in relation to depression, anxiety, and quality of life of patients with HF. Morais et al., ${ }^{10}$ examined and correlated symptoms of depression and anxiety with quality of life in HF, not involving any type of intervention.
They concluded that depression was the variable that had the strongest correlation with quality of life. Furthermore, they highlighted the lack of studies assessing outpatients. Quality of life was moderately affected, especially in the physical dimension, which is consistent with the present study. Therefore, the innovative feature of this study, which consisted of a short-term psychological intervention conducted at a clinic that specializes in HF, was evidenced, and the results demonstrated its positive effect on depression and quality of life of patients.

Although there was no statistical significance between groups in the results for anxiety, a slight improvement in the severity of these symptoms was observed in IG. In other words, patients with moderate and severe anxiety scores had them reduced to mild, minimal, or moderate. Lundgren 


\begin{tabular}{|c|c|c|c|c|}
\hline Characteristics & $\begin{array}{l}\text { Control } \\
(n=16)\end{array}$ & $\begin{array}{l}\text { Intervention ( } \\
\quad=16)\end{array}$ & $\begin{array}{c}\text { Total } \\
(\mathrm{n}=32)\end{array}$ & p-value \\
\hline Age, Yearst & $63.3 \pm 12.7$ & $65.3 \pm 10.6$ & $64.3 \pm 11.6$ & $0.644 \S$ \\
\hline Sex, Male* & $8(50.0)$ & $8(50.0)$ & $16(50.0)$ & $0.638 \ddagger$ \\
\hline Education, Elementary school* & $13(81.3)$ & $14(87.5)$ & $27(84.4)$ & $0.499 \ddagger$ \\
\hline Marital status, Married* & $6(37.5)$ & $7(43.8)$ & $13(40.6)$ & $0.869 \ddagger$ \\
\hline Occupation, Retired ${ }^{*}$ & $5(31.3)$ & $8(50.0)$ & $13(40.6)$ & $0.085 \ddagger$ \\
\hline Hometown, São Gonçalo* & $7(43.8)$ & $10(62.5)$ & $17(53.1)$ & $0.581 \ddagger$ \\
\hline Income, US\$200 - US $\$ 500^{*}$ & $7(43.8)$ & $7(43.8)$ & $14(43.8)$ & $0.817 \ddagger$ \\
\hline Living alone, $\mathrm{No}^{*}$ & $11(68.8)$ & $14(87.5)$ & $25(43.8)$ & $0.197 \ddagger$ \\
\hline Caregiver, $\mathrm{No}^{*}$ & $11(68.8)$ & $12(75.0)$ & $23(71.9)$ & $0.500 \ddagger$ \\
\hline Hospitalization in the past year, $\mathrm{No}^{*}$ & $12(75.0)$ & $12(75.0)$ & $24(75.0)$ & $0.657 \ddagger$ \\
\hline History of psychotropic drug use, $\mathrm{No}^{*}$ & $13(81.3)$ & $11(68.8)$ & $24(75.0)$ & $0.240 \ddagger$ \\
\hline Children, Yes* & $14(87.5)$ & $14(87.5)$ & $28(87.5)$ & $0.700 \ddagger$ \\
\hline Functional class, NYHA I* & $6(37.5)$ & $12(75.0)$ & $18(56.3)$ & $0.100 \ddagger$ \\
\hline Arterial hypertension, Yes* & $13(81.3)$ & $12(75.0)$ & $25(78.1)$ & $0.500 \ddagger$ \\
\hline Diabetes mellitus, Yes* & $4(25.0)$ & $5(31.3)$ & $9(28.1)$ & $0.500 \ddagger$ \\
\hline Smoking, $\mathrm{No}^{*}$ & $13(81.3)$ & $13(81.3)$ & $26(81.3)$ & $0.673 \ddagger$ \\
\hline Alcoholism, $\mathrm{No}^{*}$ & $14(87.5)$ & $14(87.5)$ & $28(87.5)$ & $0.700 \ddagger$ \\
\hline Independence, Yes* & $10(62.5)$ & $12(75.0)$ & $22(68.8)$ & $0.720 \ddagger$ \\
\hline
\end{tabular}

et al., ${ }^{22}$ also concluded in their study of 64 participants that there was no difference in intervention between groups from the internet-based cognitive behavioral therapy (CBT) for depression. However, they found an intragroup difference in this outcome, describing an improvement in symptoms.

Depressive symptoms can be confused with HF symptoms such as fatigue, changes in sleep, and appetite. Also, periods of sadness do not necessarily represent a depressive condition. For this reason, medical assessment with proper use of screening instruments is essential. ${ }^{23}$ It is worth mentioning that this patient profile tends to have experienced several losses intrinsic to their discourse, including health, profession, role in the family, in society, and in the marriage, leisure, and self-esteem. Within this context of vulnerability, patients face frequent and evolutionary limitations that may generate sadness or even depression.

Studies have shown that depression increases the number of readmissions, ${ }^{9}$ as self-care is greatly impaired. Clinical outcomes are impacted by this comorbidity.
A survey ${ }^{24}$ showed that depressive symptoms and social isolation influenced the prognosis and survival (75\% in up to 1 year) of patients waitlisted for heart transplant, and individuals without this condition had a survival of up to 8 years after transplant. The authors concluded on the importance of well-defined screening and intervention in patients at risk.

The Brazilian Guideline on Heart Failure ${ }^{3}$ and other studies emphasize the importance of psychological monitoring to patients with $\mathrm{HF}$, especially in relation to depression. However, there are still few studies, especially RCTs, on psychotherapy in HF. Some research using CBT is described in the scientific literature, but with limitations in terms of sample, intervention time, and risk of bias. ${ }^{25}$ Studies on cardiology and psychoanalysis were found in the literature, but not specific studies using the psychoanalytic approach in an HF outpatient setting. Therefore, this is a pioneer study using this approach in this patient profile with these outcomes. 
Table 2 - Affected areas, self-perception, expectations, and role in treatment (n = 32). Niterói, RJ, Brazil, 2019

\begin{tabular}{|c|c|c|c|}
\hline Variables & $\begin{array}{l}\text { Control } \\
(n=16)\end{array}$ & $\begin{array}{c}\text { Intervention } \\
(\mathrm{n}=16)\end{array}$ & p-value \\
\hline \multicolumn{4}{|l|}{ Affected areas } \\
\hline Emotions ${ }^{\prime \prime}$ & $6(37.5)$ & $6(37.5)$ & 0.642 \\
\hline Marriage $^{+}$ & $2(12.5)$ & $3(18.8)$ & 0.500 \\
\hline Family" & $4(25.0)$ & $6(37.5)$ & 0.352 \\
\hline Work" & $5(31.3)$ & $6(37.5)$ & 0.500 \\
\hline Friends ${ }^{+}$ & $3(18.8)$ & $3(18.8)$ & 0.673 \\
\hline Religion $^{+}$ & 0 & $2(12.5)$ & 0.242 \\
\hline None $^{+}$ & $2(12.5)$ & $2(12.5)$ & 0.700 \\
\hline Self-perception" & & & 0.548 \\
\hline Healthy & $4(25.0)$ & $6(37.5)$ & \\
\hline Sick without significant limitations & $4(25.0)$ & $5(31.3)$ & \\
\hline Sick with significant limitations & $8(50.0)$ & $5(31.3)$ & \\
\hline Expectations $^{\dagger}$ & & & 0.584 \\
\hline Healing & $6(37.5)$ & $7(43.8)$ & \\
\hline Self-care and better quality of life & $9(56.3)$ & $9(56.3)$ & \\
\hline None & $1(6.3)$ & 0 & \\
\hline Role in treatment & & & 0.500 \\
\hline Engaged and following all guidelines & $13(81.3)$ & $12(75.0)$ & \\
\hline Somewhat engaged and not always following all guidelines & $3(18.8)$ & $4(25.0)$ & \\
\hline Never following all guidelines & 0 & 0 & \\
\hline
\end{tabular}

\begin{tabular}{|c|c|c|c|c|c|c|c|}
\hline Scores & $\begin{array}{c}\text { Control } \\
\text { Initial }(n=16)\end{array}$ & $\begin{array}{l}\text { Intervention } \\
\text { Initial }(n=16)\end{array}$ & $\begin{array}{l}\text { p-value } \\
\text { Initial }\end{array}$ & $\begin{array}{c}\text { Control } \\
\text { Final }(n=16)\end{array}$ & $\begin{array}{l}\text { Intervention } \\
\text { Final }(n=16)\end{array}$ & $\begin{array}{c}\mathrm{p} \text {-value } \\
\text { Final }\end{array}$ & Cohen's d \\
\hline Anxiety $^{+}$ & $8.5(4.00-26.50)$ & $13.5(3.75-20.50)$ & 0.956 & $11.00(5.00-23.00)$ & $8.00(3.00-14.00)$ & 0.196 & - \\
\hline Depression $^{+}$ & $19.5(9.5-29.00)$ & $12.5(6.5-19.25)$ & 0.102 & $11.50(5-23.75)$ & $8.25(2.25-17.00)$ & 0.035 & - \\
\hline Quality of life" & $46.5 \pm 24.0$ & $37.4+22.4$ & 0.276 & $48.6 \pm 27.8$ & $25.3 \pm 18.3$ & 0.009 & 0.593 \\
\hline
\end{tabular}

Physical and emotional symptoms have significant impacts on quality of life. ${ }^{10}$ A Brazilian study that used the same outcomes and the same scales concluded that quality of life was moderately affected, with the physical dimension being the most impacted, ${ }^{10}$ as shown in the present study.
Another study ${ }^{26}$ described the effects of a repetitive monitoring and education program on quality of life of outpatients with HF. The results were positive both for the total scores and for each dimension. The long-term program included a multidisciplinary team (nurses, psychologists, nutritionists, social workers, and pharmacists) and 
supported the results, despite differences in intervention duration and technique.

Bordoni et al., ${ }^{27}$ described anxiety as a neglected symptom, which increases hospitalization rates, and a gap in the scientific literature. It is often related to a high expectation or even to worry or fear, commonly described by patients with HF. Lack of social and/or family support and situations of socioeconomic vulnerability may aggravate these symptoms. Studies have described the relationship of this condition with the absence of social support and inability to deal with stressful situations. ${ }^{26}$ Such studies suggested that stress is a risk factor for acute myocardial infarction and recommended interventions focusing on prevention. Generalized anxiety disorder, for instance, may increase the risk of cardiovascular events, therefore being predictive of hospital complications and deaths. ${ }^{11}$

Mourning experiences were described by participants and reported by Knebel \& Marin ${ }^{28}$ in their study, which assessed psychosocial factors and their psychological management ${ }^{27}$. Losing beloved ones was related to symptoms of depression and anxiety, in addition to loss of vitality, productivity, and sexuality.

A small sample $(n=32)$, only one professional to work with all participants, and irregular attendance by some of them (financial difficulties, personal and/or medical appointments, discouragement, health problems, etc.) were some of the limitations of this study. Another limitation was the extreme difficulty in contacting patients, as despite seeking constant updating, the team found incorrect or unavailable phone numbers. Using registered letters was an ineffective alternative to contact patients.

Investigating patients with HF promoted reflections and considerations for future studies, especially those using a qualitative approach. The patients' statements portrayed their vulnerability, as well as individual and collective physical and psychological suffering. Thus, future investigations should describe and analyze the content of the participants' complaints; the helpless state of patients with HF; mourning; the experience of the study psychologist at the specialty clinic; and patients' perception of the psychotherapeutic process.

We hope that the experience described in this paper can be used in other HF outpatient settings. Short-term psychotherapy using psychoanalytic listening proved to be effective in improving quality of life and depression. The semistructured, flexible treatment plan made it possible to approach patients, who were able to express their anxieties, fears, and concerns, as well to devise better ways to face illness and their personal issues. An alternative method for a high number of users is group therapy, which was not tested this time but is a future research opportunity. Moreover, other researchers are encouraged to expand this study by investigating the benefits of this process to hospital readmissions and assessing gratitude and resilience in this patient profile.

\section{Conclusion}

This study tested a short-term psychological intervention using the perspective of psychoanalysis and assessed its effect on anxiety, depression, and quality of life of patients with HF seen at a specialty clinic. The results demonstrated a positive effect of the proposed intervention on quality of life and depression in this patient profile.

\section{Author contributions}

Conception and design of the research, Writing of the manuscript, Analysis and interpretation of the data:Rocha, ICAO. Acquisition of data: Figueiredo, LS, Cruz, DCS, Freitas, RVM, Oliveira, SX. Critical revision of the manuscript for intellectual content, Supervision / as the major investigador: Cavalcanti, ACD, Mesquita, ET. Analysis and interpretation of the data: Pereira, JMV.

\section{Potential Conflict of Interest}

No potential conflict of interest relevant to this article was reported.

\section{Sources of Funding}

There were no external funding sources for this study.

\section{Study Association}

This article is part of the thesis of master submitted by Isaura Cristina Azambuja de Oliveira Rocha, from Universidade Federal Fluminense.

\section{Ethics approval and consent to participate}

This study was approved by the Ethics Committee of the Hospital Universitário Antônio Pedro (CEP/HUAP) under the protocol number CAAE: 57827916.3.0000.5243. All the procedures in this study were in accordance with the 1975 Helsinki Declaration, updated in 2013. Informed consent was obtained from all participants included in the study. 


\section{References}

1. World Health Organization. (WHO). Time to deliver: report of the WHO independent high-level commission on noncommunicable diseases. Geneva: 2018.

2. Junqueira L, Pina M. A psicologia cardíaca e a intervenção mentecoração: novos paradigmas para a prevenção das enfermidades cardíacas e o tratamento psicológico de pacientes cardíacos. Psychiatry on line Brasil. 2017 Nov;22. [Acesso 22 jun 2019]. Disponível em: https://www. polbr.med.br/ano17/art0317.php.

3. Rohde LE, Montera MW, Bocchi EA, Clausell N, Albuquerque DC, Rassi S. Comitê Coordenador da Diretriz de Insuficiência Cardíaca. Diretriz Brasileira de Insuficiência Cardíaca Crônica e Aguda. Arq Bras Cardiol. 2018;111(3):436-539.

4. Bocchi EA, Braga FGM, Ferreira SMA, Rohde LEP, Oliveira WA, Almeida DR, et al. III Diretriz Brasileira de Insuficiência Cardíaca Crônica. Arq Bras Cardiol. 2009;93(1 supl.1):1-71.

5. Fonseca C, Brás D, Araújo I, Ceia F. Heart failure in numbers: Estimate for the 21st century in Portugal. Rev Port Cardiol. 2018;37(2):97-104.

6. Fonseca C, Brito D, Cernadas R, Ferreira J, Franco F, Rodrigues T, et al. For the improvement of Heart Failure treatment in Portugal - Consensus statement. Rev Port Cardiol. 2017;36(1):1-8.

7. Mansur AP, Favarato D. Trends in mortality rate from cardiovascular disease in Brazil, 1980-2012. Arq Bras Cardiol. 2016;107(1):20-5.

8. Albuquerque D, Souza Neto JD, Bacal F, Rohde LEP, Bernardez-Pereira $\mathrm{S}$, Berwanger $\mathrm{O}$, et al. I Brazilian registry of heart failure - clinical aspects, care quality and hospitalization outcomes. Arq Bras Cardiol 2015;104(6):433-42.

9. Karataş MB, Şahan E, Özcan KS, Çanga Y, Güngör B, Onuk T, et al. Anxiety, depression, and general psychological distress in patients with coronary slow flow. Arq Bras Cardiol. 2015;105(4):362-70.

10. Morais ER, Carvalho CS, Euqueres L, Viana FP, Fantinati AMM, Rassi S. Quality of life and symptoms of depression and anxiety in patients with chronic heart failure. Estudos Vida Saúde. 2018;45:71-9.

11. Dekker RL, Lennie TA, Doering LV, Chung ML, Wu JR, Moser DK. Coexisting anxiety and depressive in patients with heart failure. Eur J Cardiovasc Nurs. 2015;3(2):168-76.

12. Cunha JA. Psicodiagnóstico-V. 5. ed. Porto Alegre: Artmed. 2007; p.237-41.

13. Goreinstein C, Andrade L. Validation of a portuguese version of the Beck depression inventory and the state trait anxiety inventory in brazilian subjects. Braz J Med Biol Res. 1996;29(4):453-7.

14. Rector TS, Kubo S, Cohn J. Patient's self-assessment of their congestive heart failure. Part 2: content, reliability and validity of a new measure, The Minnesota living with heart failure questionnaire. Heart Fail. 1987;198-219.
15. Carvalho VO, Guimarães GV, Carrara D, Bacal F, Bocchi EA. Validation of the portuguese version of the Minnesota living with heart failure questionnaire. Arq Bras Cardiol. 2009;93(1):39-44.

16. Santos JJ, Plewka JE, Brofman PR. Quality of life and clinical indicators in heart failure: a multivariate analysis. Arq Bras Cardiol. 2009;93(2):159-66.

17. Guerra TRB. Impacto prognóstico dos biomarcadores serotonina e fator diferenciador neutrófilo cerebral (BDNF) em pacientes com insuficiência cardíaca sistólica [tese]. Niterói: Universidade Federal Fluminense; 2014.

18. Freedland KE, Carney RM, Rich MW, Steinmeyer BC, Rubin EH. Cognitive behavior therapy for depression and self-care in heart failure patients: a randomized clinical trial. JAMA Intern Med. 2015;175(11):1773-82.

19. Brasil. Resolução no 466, de 12 de dezembro de 2012. Aprova normas regulamentadoras de pesquisas envolvendo seres humanos. Diário Oficial da União 13 jun 2013; Seção1: 59.

20. Schulz KF, Altman DG, Moher D, CONSORT Group. CONSORT 2010 statement: updated guidelines for reporting parallel group randomised trials. BMJ. 2010 Mar 23;340:c332.

21. Espírito Santo H, Daniel F. Calculating and reporting effect sizes on scientific papers (1): $\mathrm{p}<0.05$ limitations in the analysis of mean differences of two groups. Port J Behav Social Res. 2015;1(1):3-16.

22. Lundgren JG, Dahlström O, Andersson G, Jaarsma T, Köhler AK, Johansson P. The effect of guided web-based cognitive behavioral therapy on patients with depressive symptoms and heart failure: a pilot randomized controlled trial. J Med Internet Res. 2016;18(8):e194.

23. Cameron OG, Ehrmann D, Pitt B. Depression, anxiety, anger and heart failure. In: Riba M, Wulsin L, Rubenfire M. Psychiatry and heart disease: the mind, brain and heart. New Jersey: John Wiley \& Sons. 2012; p.34-8.

24. Spaderna H, Zittermann A, Reichenspurner H, Ziegler C, Smits J, Weidner G. Role of depression and social isolation at time of waitlisting for survival 8 years after heart transplantation. J Am Heart Assoc. 2017;6(12):1-11.

25. Jeyanantham K, Kotecha D, Thanki D, Dekker R, Lane DA. Effects of cognitive behavioural therapy for depression in heart failure patients: a systematic review and meta-analysis. Heart Fail Rev. 2017;22(6):731-41.

26. Cruz FD. A avaliação dos componentes da qualidade de vida na insuficiência cardíaca. [tese]. São Paulo: Universidade de São Paulo; 2010.

27. Bordoni B, Marelli F, Morabito B, Sacconi B. Depression and anxiety in patients with chronic heart failure. Future Cardiol. 2018;14(2):115-9.

28. Knebel IL, Marin AH. Psychosocial factors associated with heart disease and clinical psychological management: perception of psychologists and patients. Rev SBPH. 2018;21(1):1-20. 


\section{Treatment Plan}

\begin{tabular}{|c|c|c|}
\hline Sessions & Description of activities & $\begin{array}{l}\text { Aspects addressed and assessed by the } \\
\text { psychologist (concepts of psychology } \\
\text { and psychoanalysis) }\end{array}$ \\
\hline $1^{\text {st }}$ & $\begin{array}{l}\text { - Explain the psychotherapeutic process thoroughly, stating the } \\
\text { importance of following the treatment plan. } \\
\text { - Identify together with patients three priority aspects for treatment. }\end{array}$ & \\
\hline $2^{\text {nd }}$ to $8^{\text {th }}$ & $\begin{array}{l}\text { - Address issues related to the disease, self-care, personal needs, life } \\
\text { expectations, personal and family history, self-perception, bonds, beliefs, } \\
\text { religiousness, etc. } \\
\text { - Clarify patients' doubts with the help of the multidisciplinary team, } \\
\text { if necessary. } \\
\text { - Invite family members, if possible, for assistance and guidance, } \\
\text { especially on how to help/facilitate/encourage patients to have better } \\
\text { adherence to treatment and better coping with the disease. } \\
\text { - Assess the possibility of adjustments in lifestyle as well as encourage } \\
\text { changes in habits, offering support and outlining coping strategies } \\
\text { (including social, family, and religious support, social, leisure, and/or } \\
\text { physical activities, public spaces, specialty clinics, etc.). } \\
\text { - Discuss the progress of the process with patients and make adjustments, } \\
\text { if necessary. } \\
\text { - Discuss the possibility of changing the priority aspects of treatment. } \\
\text { - Provide feedback to patients. } \\
\text { - Address changes in personal choices. } \\
\text { - Address the impacts and limitations of the disease and think of } \\
\text { possibilities or alternatives for everyday life, be it work, social interaction, } \\
\text { or family environment. }\end{array}$ & $\begin{array}{l}\text { - Initial demands } \\
\text { - Diagnosis = traumatic event (intense } \\
\text { event that individuals are unable to react } \\
\text { properly and that causes pathogenic } \\
\text { effects on psychic organization). } \\
\text { - Representations of the disease and } \\
\text { fantasies (subjects represent, somewhat } \\
\text { distorted by defensive processes, the } \\
\text { fulfillment of a wish) } \\
\text { - Assessment of bonds (affective bonds) } \\
\text { and affection } \\
\text { - Psychoeducation } \\
\text { - Psychic ambivalences and conflicts } \\
\text { - Defense mechanisms (aims to } \\
\text { reduce or eliminate any danger to the } \\
\text { biopsychological individual) } \\
\text { - Conscious vs. unconscious }\end{array}$ \\
\hline $9^{\text {th }}$ & $\begin{array}{l}\text { - Address treatment closure and aspects related to the termination of this } \\
\text { bond, as well as highlight the gains obtained during therapy. }\end{array}$ & $\begin{array}{l}\text { - Free association method (connection } \\
\text { between two or more psychic elements }\end{array}$ \\
\hline $10^{\text {th }}$ and $11^{\text {th }}$ & - Address some possible issues. & $\begin{array}{c}\text { spontaneously) } \\
\text { - Insights }\end{array}$ \\
\hline $12^{\text {th }}$ & $\begin{array}{l}\text { - End the process, reinforcing all topics covered, and hand over the } \\
\text { discharge guidance sheet. } \\
\text { - Deliver referral to patients who need to continue treatment. } \\
\text { - Administer a final questionnaire. } \\
\text { - New administration of the Beck Anxiety/Depression Inventory (BAI } \\
\text { and BDI) and the Minnesota Living with Heart Failure Questionnaire } \\
\text { (MLHFQ) by a psychologist or a nursing student. }\end{array}$ & \\
\hline
\end{tabular}

